\title{
Care for newborns by primipara mothers in developing countries: scooping review
}

\author{
Ova Jayanti ${ }^{*}$, Farida Kartini², Sri Ratnaningsih ${ }^{3}$ \\ 1,2,3 Faculty of Health Sciences, 'Aisyiyah University of Yogyakarta,, Indonesia \\ ${ }^{1}$ Ovajayanti58@yahoo.com*; ${ }^{2}$ faridakartini@unisayogya.ac.id; ${ }^{3}$ ratna_ningsih@unisayogya.ac.id \\ Submission date: 24 Maret 2021, Receipt date: 26 April 2021, Publication date: 1 Juli 2021
}

\begin{abstract}
Almost every parent feels the joy of welcoming their healthy baby. On the other hand, the presence of the baby also raises worry and sadness regarding his care. Scoping Review aims to map the literature on the care of newborns by primiparous mothers in developing countries. Review literature based on the Arksey and O'Malley framework using Pubmed, Sciencedirect, Wiley, and Gray Literature. Based on the mapping results from the 7 articles included, 3 themes were obtained, namely sociodemographic characteristics, aspects of newborn care and cultural factors.
\end{abstract}

Keywords: newborn care, primiparous mothers, developing countries

\section{INTRODUCTION}

The newborn period is a period of adjustment from intra-uterine life to extrauterine life. Switch from absolute dependence on mothers to physiological independence (Aydin, 2017), the postpartum period is a critical transition period for mothers, babies, and families physiologically, emotionally, and socially. In both developed and developing countries, the main concern for mothers and babies is mostly during pregnancy and childbirth, while the actual situation is just the opposite because the risk of morbidity and mortality of mothers and newborns is more common during the puerperium (Prawirohardjo, 2016)

According to the World Health Organization (WHO) the world's neonatal mortality rate decreased from 5 million in 1990 to 2.4 million in 2019, where $47 \%$ of deaths occurred in children under 5 years of age, one-third died within 24 hours of birth and three-quarters of deaths in the first week of life (Hug et al., 2019). The highest contributor to neonatal deaths occurred in Sub Saharan Africa with 27 deaths per 1,000 live births in 2019, Central and South Asia with 24 deaths per 1,000 live births (Hug et al., 2019). Where a child born in Sub Saharan Africa or South Asia is 10 times more likely to die in the first month of life than a child born in a developed country with high income (Tekelab et al., 2019)

According to the United Nations Children's Fund (UNICEF), in recent decades, mortality in infants aged 0-28 days to children aged five years is still high among lowincome developing countries (Tekelab et al., 2019). The risk of newborn death varies between and within countries. Babies born to families with low economic status are twice as likely to die during the newborn period than babies born to families with middle and upper-economic status. Babies born to mothers without education are at almost twice the 
risk of dying at birth compared to babies born to mothers with at least secondary education (Goldenberg \& McClure, 2015). In other words, infant mortality does not only occur due to medical causes such as prematurity and pneumonia but also to sociodemographic conditions.

The birth of a child poses a fundamental challenge to the established structure of family interactions and the care of the newborn. When a baby is born for the first time, the mother may feel confused about caring for one (Erfina et al., 2019). Even routine and simple tasks such as prevention of heat loss, umbilical cord care, and breastfeeding can make mothers anxious, especially if the mother has never spent her time on things related to baby care before (Herawati, 2015). The main objective of the study is to collect and map the literature on newborn care by primiparous mothers in developing countries.

\section{RESEARCH METHODS}

This review uses the methodology for review and classification suggested by (Arksey \& O'malley, 2005) and further developed by (Levac et al., 2010) There are five stages, namely: (A) identification of research questions, (B) identification of relevant studies, (C) selection of articles, (D) data charting, (E) presentation of data and results.

\section{Stage 1: Identification of Research Questions}

The use of PEOS helps to identify key concepts in the focus of the question, develop appropriate search terms to describe the problem, and define inclusion and exclusion criteria. PEOS is used to identify elements of qualitative research questions so that PEOS is judged appropriate to use.

Arksey \& O'malley (2005) suggest starting a broader research question and then narrowing it down to focus on the scope of the literature you want to know. The research question used is how is the care of newborns by primiparous mothers in developing countries?

\section{Stage 2: Identification of Relevant Studies}

To be as complete as the search terms, first consulted with an expert, namely a supervisor, then searched using 3 databases (Pubmed, Sciencedirect, Wiley) and gray literature from google scholar and specific websites from WHO and UNICEF. A search combination that is developed literally on keywords, medical terms, and the main subject combined with a bundle of AND or OR operators. To specify the search literature search is limited to journals published in the last 10 years.

\section{Stage 3: Selection of Articles}

Inclusion and exclusion criteria are needed to filter the number of articles produced to ensure relevance (Levac et al., 2010) Inclusion criteria include primary research, articles in English and Indonesian, articles that discuss the experiences of primiparous mothers, both from the perspective of fathers and grandmothers in carrying out care for newborns. Exclusion criteria included opinion articles, articles that discussed infants with abnormalities or risks, and articles that discussed mothers with postpartum blues. 
A search with 3 databases and gray literature found 363 articles. Then the researchers imported the article into the reference manager and deleted the duplicate articles. Furthermore, the researcher conducted a two-step screening for determining the eligibility of citations based on inclusion and exclusion criteria. First, review the title and abstract, then the researcher will review in full text to determine the feasibility of the articles that have been selected in the first step (Figure 1).

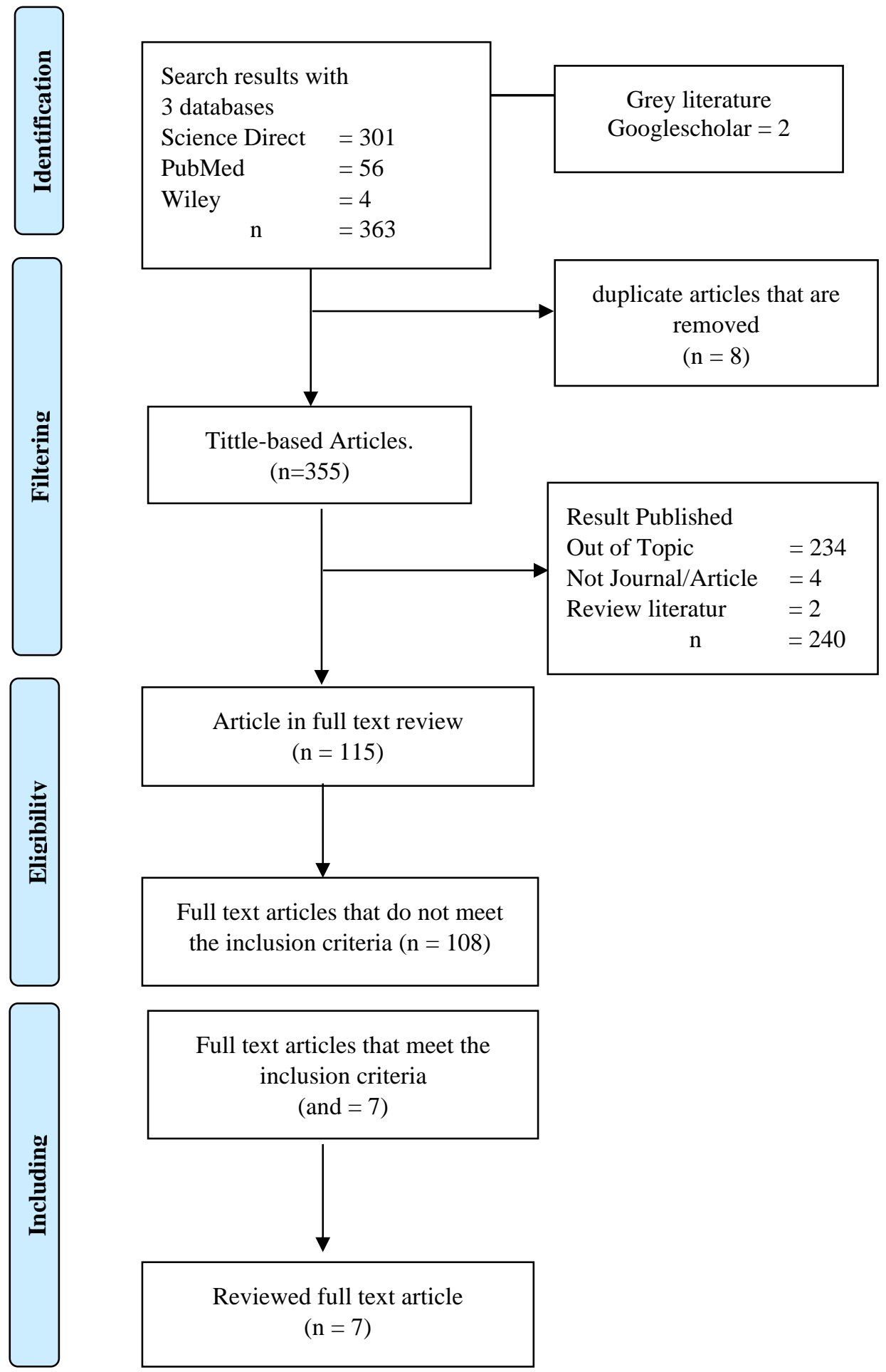

Figure 1. Prisma Flow Chart 


\section{Stage 4: Charting Data}

Table 1. Charting Data

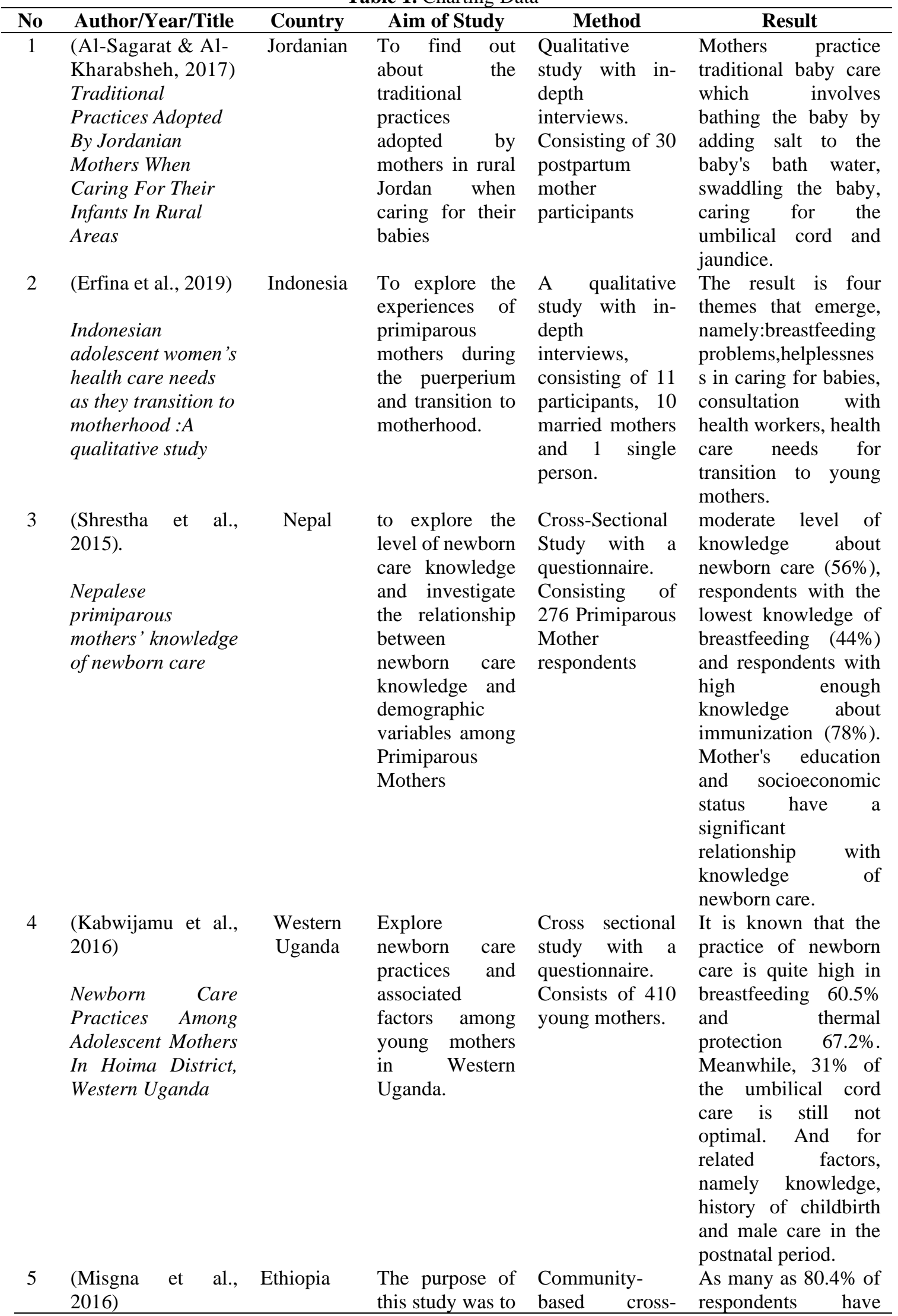




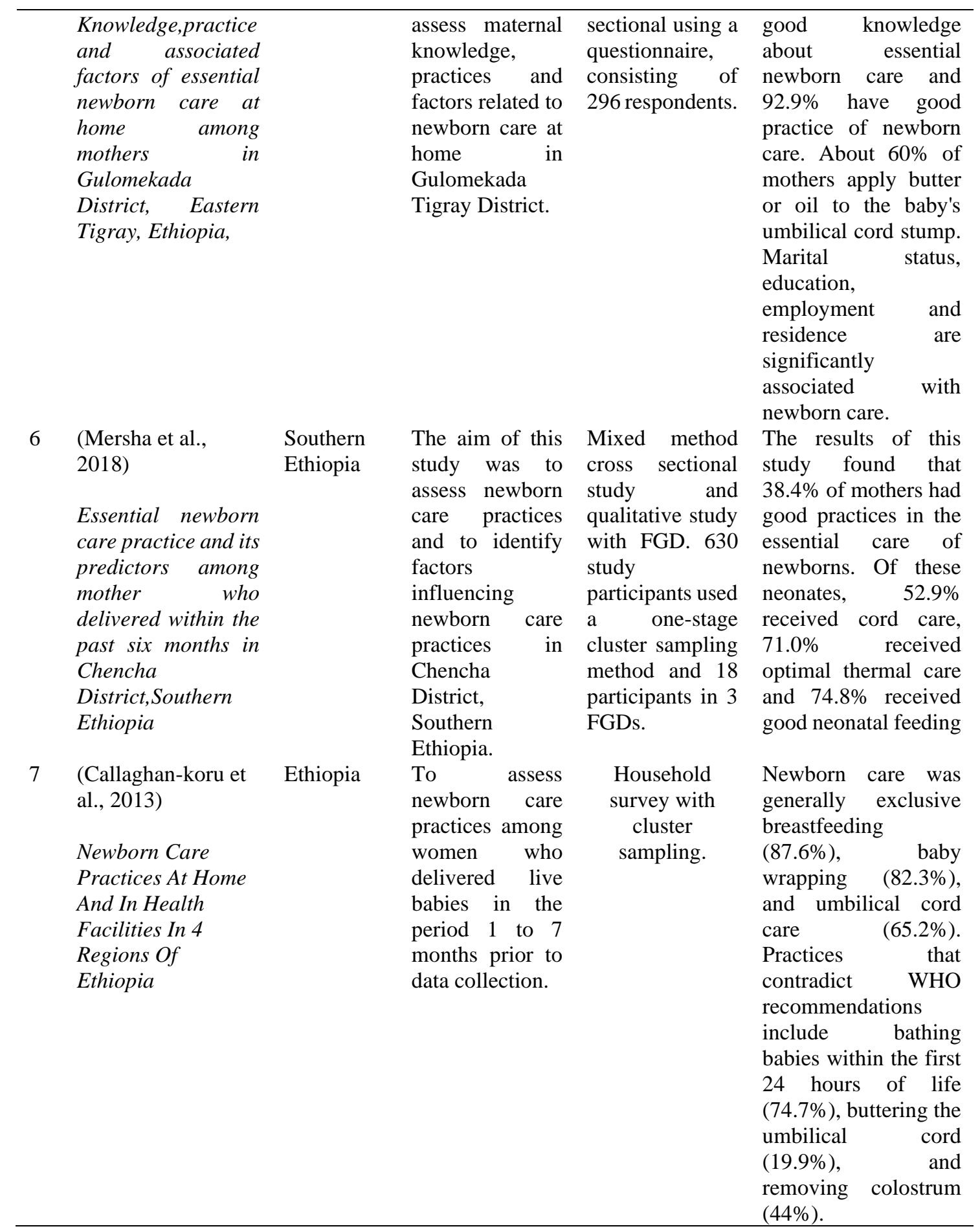




\section{Stage 5: Presentation of Data and Results}

In line with Arksey \& O'malley (2005) did, researchers took a three-phase approach, namely compiling, summarizing, and reporting the results. First, a descriptive numerical analysis includes the number of articles, year of publication, and type of study. Second, strengths and weaknesses in the literature are identified through thematic analysis of the studies attached to the report. The final phase is a review of the implications of the findings regarding future research, practice, and policy.

\section{RESULTS AND DISCUSSION}

The results of the scooping review, based on the 7 included articles. 2 of them are qualitative research, 3 cross-sectional, 1 mixed method, and 1 household survey. The majority of the research was conducted in Ethiopia. Ethiopia is the country with the highest neonatal mortality rate in the world (Berhe et al., 2017)

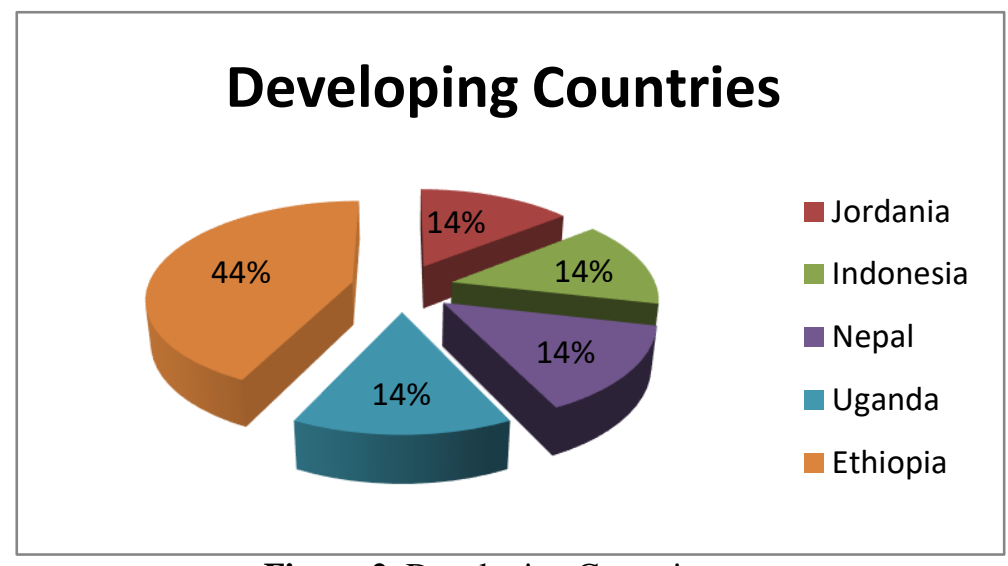

Figure 2. Developing Countries

The mapping results of 7 articles according to the study criteria are believed to have high credibility and reliable results. Researchers set several themes as follows:

Table 2. Mapping Themes

\begin{tabular}{ll}
\hline \multicolumn{1}{c}{ Themes } & Articles Number \\
\hline Sociodemographic characteristics & \\
Knowledge & $5,6,7$ \\
Education & 5 \\
Economic status & 3 \\
Residence & 1,5 \\
Helplessness & 2 \\
Resources & 1,2 \\
Aspects of newborn care & \\
Umbilical cord care & $1,4,5,6$ \\
Breastfeeding & $2,3,4,6,7$ \\
Prevention of hypothermia & $1,4,6,7$ \\
Immunization & 3 \\
Cultural factors & \\
Traditional practice & $1,5,7$ \\
\hline
\end{tabular}




\section{Sociodemographic Characteristics}

Based on the sociodemographic characteristics of primiparous mothers. The majority of mothers live in rural areas (Al-Sagarat \& Al-Kharabsheh, 2017; Callaghankoru et al., 2013; Kabwijamu et al., 2016; Misgna et al., 2016; Shrestha et al., 2015) with a fairly high level of knowledge of newborn care by primiparous mothers (Callaghan-koru et al., 2013; Mersha et al., 2018; Misgna et al., 2016). Higher awareness has a significant relationship with education. The higher the mother's education level, the more knowledge she has. Conversely, the lack of maternal education will hamper the mother's attitude developments towards the newly introduced values for providing care for newborns (Misgna et al., 2016)

Mother's knowledge is also related to economic status. Mothers with high economical-status have a high awareness of newborn care. Meanwhile, mothers with low economic status have less awareness of newborn care as well (Shrestha et al., 2015). To find out the economic status of a family, it can be seen from income. It is known that 12 out of 13 women reported having a low household income per year (Suplee et al., 2014) Low income makes it difficult for mothers to meet their needs, especially for their babies. If this situation continues. It is very vulnerable for primiparous mothers to experience depression during postpartum. As a result, mothers are willing to choose unsafe abortion to suppress family needs if the baby is born (Gbogbo, 2020)

In developing countries, women's autonomy in making decisions is very low (Jahan et al., 2015). In addition to the high knowledge of primiparous mothers. Primiparous mothers must also be given space to express themselves. Primiparous mothers should be given the opportunity. Instinctively, women have maternal instincts, naturally growing and developing in every mother. Sometimes what you want is different from what you get. Young mothers feel helpless because they are not given the opportunity to be involved and participate in caring for their babies (Erfina et al., 2019). On the other hand, mothers also have dualistic responsibilities between cultural expectations and the health system (Buser et al., 2020). Mothers are interested in engaging in traditional care rituals. Meanwhile, at the same time mothers are encouraged to make visits to health facilities (Buser et al., 2020)

Based on sources of information on newborn care, mothers get information from maternal and child health (KIA) books (Erfina et al., 2019), health workers (Callaghankoru et al., 2013), parents, grandmothers and grandfathers (Al-Sagarat \& AlKharabsheh, 2017). Mothers consider whatever their parents and senior siblings tell and teach is the right and right action.

\section{Aspects of Newborn Care}

The aspects of essential newborn care are umbilical cord care, prevention of hypothermia, breastfeeding, and immunization. Of these five aspects, there are four aspects of care that need to be reviewed by researchers, namely umbilical cord care, prevention of hypothermia, and breastfeeding. When viewed from the knowledge of newborn care in developing countries is quite good. However, in its implementation, it needs to be highlighted again because there are still many traditional newborn treatments that are not suitable evidence-based. 


\section{Traditional Factors}

Some of the wrong traditional practices can be a cause of morbidity and mortality for newborns, especially in developing countries. In Jordan traditional practices are generally present in society, especially those related to the care of newborns, the grandparents in Jordan bathe their newborn grandchildren in saltwater, they believe that bathing with salt water aims to prevent babies from diaper rash (Al-Sagarat \& AlKharabsheh, 2017)

In umbilical cord care, a common practice of primiparous mothers is the use of neomycin powder, mothers believe that neomycin powder will accelerate umbilical healing(Al-Sagarat \& Al-Kharabsheh, 2017). Traditional umbilical cord care is also performed by young mothers in West Uganda. It is known that more than $50 \%$ of mothers give neomycin powder, herbal medicine, and the most commonly used salty water. Only a few mothers perform clean and dry cord care (Kabwijamu et al., 2016)

Traditional practices that contradict WHO recommendations are also found in Ethiopia, where 296 post-partum mothers, about $60 \%$ of mothers still apply butter or oil to the umbilical cord (Misgna et al., 2016). Mothers bathed their babies in the first 24 hours of life quite high (74.7\%) and removed colostrum (44\%). In some traditional societies, colostrum is considered damaged milk and is not good for babies because it is yellowish.

\section{CONCLUSION}

This scoping review presents a synthesis of studies describing the care of newborns by primiparous mothers in developing countries. Based on sociodemographic characteristics, the majority of primipara mothers have a high enough knowledge, upper secondary education level, have incomes below the national wage, live in rural areas, and have a minority role because they are considered incapable of caring for babies. In addition, the care of newborns in developing countries is also influenced by cultural factors.

In some countries the cultural influence is still very high especially in terms of matters related to the care of newborns. Cultural influences lead to a gap between knowledge and practice. Some articles mention that the knowledge of primipara mothers is quite high but has low newborn care practices. Like a grandmother in Ethiopia mixing salt in a baby's bath water, mothers in jordhania give spices to the umbilical cord. Cultural influences are inevitable in life. Therefore, cultural perception must be seen from two sides, first the culture can be seen as giving a positive effect and culture can also be seen as giving a negative effect. It is not a culture that has to adapt to health sciences, but health sciences that adapt to people's culture. Health workers should be able to provide understanding to the public about the care of newborns in accordance with evidence based. 


\section{REFERENCES}

Al-Sagarat, A. Y., \& Al-Kharabsheh, A. (2017). Traditional Practices Adopted By Jordanian Mothers When Caring For Their Infants In Rural Areas. African Journal Of Traditional, Complementary And Alternative Medicines, 14(1), 1-9. Https://Doi.Org/10.21010/Ajtcam.V14i1.1

Arksey, H., \& O'malley, L. (2005). Scoping Studies: Towards A Methodological Framework. International Journal Of Social Research Methodology, 8(1), 19-32. Https://Doi.Org/10.1080/1364557032000119616

Aydin, R. (2017). Birth Journey Of A Newborn: Transition From Intrauterine To Extrauterine Life. New Trends And Issues Proceedings On Advances In Pure And Applied Sciences, 8(8), 01-06. Https://Doi.Org/10.18844/Gjapas.V0i8.2780

Berhe, M., Medhaniye, A. A., Kahsay, G., Birhane, E., \& Abay, M. (2017). Essential Neonatal Care Utilization And Associated Factors Among Mothers In Public Health Facilities Of Aksum Town, North Ethiopia, 2016. Plos One, 12(4). Https://Doi.Org/10.1371/Journal.Pone.0175902

Buser, J. M., Moyer, C. A., Boyd, C. J., Zulu, D., Ngoma-Hazemba, A., Mtenje, J. T., Jones, A. D., \& Lori, J. R. (2020). Cultural Beliefs And Health-Seeking Practices: Rural Zambians' Views On Maternal-Newborn Care. Midwifery, 85, 102686. Https://Doi.Org/10.1016/J.Midw.2020.102686

Callaghan-Koru, J. A., Seifu, A., Tholandi, M., Graft-Johnson, J. De, Daniel, E., Rawlins, B., Worku, B., \& Baqui, A. H. (2013). Newborn Care Practices At Home And In Health Facilities In 4 Regions Of Ethiopia.

Erfina, E., Widyawati, W., Mckenna, L., Reisenhofer, S., \& Ismail, D. (2019). Exploring Indonesian Adolescent Women's Healthcare Needs As They Transition To Motherhood: A Qualitative Study. Women And Birth, 32(6), E544-E551. Https://Doi.Org/Https://Doi.Org/10.1016/J.Wombi.2019.02.007

Gbogbo, S. (2020). Early Motherhood: Voices From Female Adolescents In The Hohoe Municipality, Ghana-A Qualitative Study Utilizing Schlossberg's Transition Theory. International Journal Of Qualitative Studies On Health And Well-Being, 15(1). Https://Doi.Org/10.1080/17482631.2020.1716620

Goldenberg, R. L., \& Mcclure, E. M. (2015). Maternal, Fetal And Neonatal Mortality: Lessons Learned From Historical Changes In High Income Countries And Their Potential Application To Low-Income Countries. Maternal Health, Neonatology And Perinatology, 1(1). Https://Doi.Org/10.1186/S40748-014-0004-Z

Herawati, T. (2015). Kemandirian Ibu Nifas Primipara Dan Perawatan Bayi Baru Lahir. Jurnal Keperawatan Terapan.

Hug, L., Alexander, M., You, D., \& Alkema, L. (2019). National, Regional, And Global Levels And Trends In Neonatal Mortality Between 1990 And 2017, With ScenarioBased Projections To 2030: A Systematic Analysis. The Lancet Global Health, 7(6), 
E710-E720. Https://Doi.Org/10.1016/S2214-109x(19)30163-9

Jahan, F., Hossain, S., Sci, K. M.-I. I. J. R. A. N. S., \& 2015, Undefined. (2015). Factors Influencing Women's Decision Making Power: Evidence From Bangladesh Urban Health Survey Data. Researchgate.Net, 40(2), 133-150.

Kabwijamu, L., Waiswa, P., Kawooya, V., Nalwadda, C. K., Okuga, M., \& Nabiwemba, E. L. (2016). Newborn Care Practices Among Adolescent Mothers In Hoima District, Western Uganda. Plos One, 11(11). Https://Doi.Org/10.1371/Journal.Pone.0166405

Levac, D., Colquhoun, H., \& O’brien, K. K. (2010). Scoping Studies: Advancing The Methodology. Implementation Science : Is, 5(1), 69. Https://Doi.Org/10.1186/17485908-5-69

Mersha, A., Assefa, N., Teji, K., Shibiru, S., Darghawth, R., \& Bante, A. (2018). Essential Newborn Care Practice And Its Predictors Among Mother Who Delivered Within The Past Six Months In Chencha District, Southern Ethiopia, 2017. Plos One, 13(12), 1-17. Https://Doi.Org/10.1371/Journal.Pone.0208984

Misgna, H. G., Gebru, H. B., \& Birhanu, M. M. (2016). Knowledge, Practice And Associated Factors Of Essential Newborn Care At Home Among Mothers In Gulomekada District, Eastern Tigray, Ethiopia, 2014. Bmc Pregnancy And Childbirth, 16(1). Https://Doi.Org/10.1186/S12884-016-0931-Y

Prawirohardjo, S. (2016). Ilmu Kebidanan Sarwono Prawirohardjo. Edisi Ke-4. Jakarta: Yayasan Bina Pustaka Sarwono Prawirohardjo.

Shrestha, S., Adachi, K., Petrini, M. A., Shuda, A., \& Shrestha, S. (2015). Nepalese Primiparous Mothers' Knowledge Of Newborn Care. Nursing \& Health Sciences, 17(3), 347-353. Https://Doi.Org/10.1111/Nhs.12193

Suplee, P. D., Gardner, M. R., \& Borucki, L. C. (2014). Low-Income, Urban Minority Women's Perceptions Of Self- And Infant Care During The Postpartum Period. Jognn - Journal Of Obstetric, Gynecologic, And Neonatal Nursing, 43(6), 803-812. Https://Doi.Org/10.1111/1552-6909.12506

Tekelab, T., Chojenta, C., Smith, R., \& Loxton, D. (2019). The Impact Of Antenatal Care On Neonatal Mortality In Sub-Saharan Africa: A Systematic Review And Meta$\begin{array}{llll}\text { Analysis. Plos } & \text { One, } & \text { 14(9), } & \end{array}$ Https://Doi.Org/10.1371/Journal.Pone.0222566 